\title{
Post-Colonoscopy Colonic Perforation Presenting With Subcutaneous Emphysema: A Case Report
}

\author{
Muhammad Khan ${ }^{\text {a }}$, Muhammad Ijaz ${ }^{\mathrm{a}}$, Sumera Bukhari ${ }^{\mathrm{a}}$, Ahmed Dirweesh ${ }^{\mathrm{a}, \mathrm{b}}$, \\ Donald Christmas $^{\text {a }}$
}

\begin{abstract}
Colonoscopy is performed for both diagnostic and therapeutic indications. Although rare, associated complications can be quite serious. The frequency of these complications depends mainly on the skills of the physicians doing the procedure, and the diagnostic or therapeutic indications. Major complications include adverse anesthetic related events, aspiration pneumonia, bleeding, and colonic perforation. We present a rare case of a post-colonoscopy perforation presenting with subcutaneous emphysema and free mediastinal, and intra-peritoneal air. The patient was successfully managed conservatively with complete resolution of symptoms.
\end{abstract}

Keywords: Colonoscopy; Perforation; Emphysema

\section{Introduction}

Colonoscopy is considered as one of the most commonly performed medical procedures and deemed to be safe. However, the complication rates are increasing as its use is growing due in part to the successful promotion of colorectal cancer screening and prevention guidelines. Post-colonoscopy, the incidence of colonic perforation (CP), is rare with an estimation of 0.19$0.21 \%$. Though intraperitoneal perforation is common, extraperitoneal perforation with pneumoperitoneum, pneumomediastinum, and subcutaneous emphysema is exceedingly rare.

\section{Case Report}

A 64-year-old African American female with past medical history significant for hypertension and cerebral aneurysm status after repair presented with sudden onset of diffuse chest and abdominal pain. She described the pain as persistent, dull in

\section{Manuscript accepted for publication February 01, 2017}

aDepartment of Internal Medicine, Saint Francis Medical Center, Seton Hall University, Trenton, NJ, USA

${ }^{b}$ Corresponding Author: Ahmed Dirweesh, Department of Internal Medicine, Saint Francis Medical Center, Seton Hall University, Trenton, NJ, USA. Email: adirweesh@stfrancismedical.org

doi: https://doi.org/10.14740/gr797w nature, non-radiating and aggravated by movement. She had a routine screening colonoscopy in the morning of admission. She also complained of shortness of breath and two episodes of non-bloody, non-bilious vomiting. Before colonoscopy, she was in her usual state of health. Her last colonoscopy was 10 years ago and was normal. For the current procedure, she had adequate bowel preparation and the findings were positive for wide mouthed diverticulosis of the sigmoid colon without other associated findings. No biopsy was performed.

Clinical examination revealed normal vital signs with subcutaneous emphysema and air crepitus at the base of her neck bilaterally and on the anterior chest wall. No rhonchi or wheeze appreciated. The abdomen was diffusely tender and distended with audible bowel sounds. The rest of her examination was normal. Plain radiography showed pneumoperitoneum as well as pneumomediastinum (Fig. 1). Computed tomography (CT) scan of the chest, abdomen and pelvis revealed massive free retroperitoneal and intraperitoneal air and massive pneumomediastinum with extensive gas dissecting throughout the "neck (Fig. 2a, b).

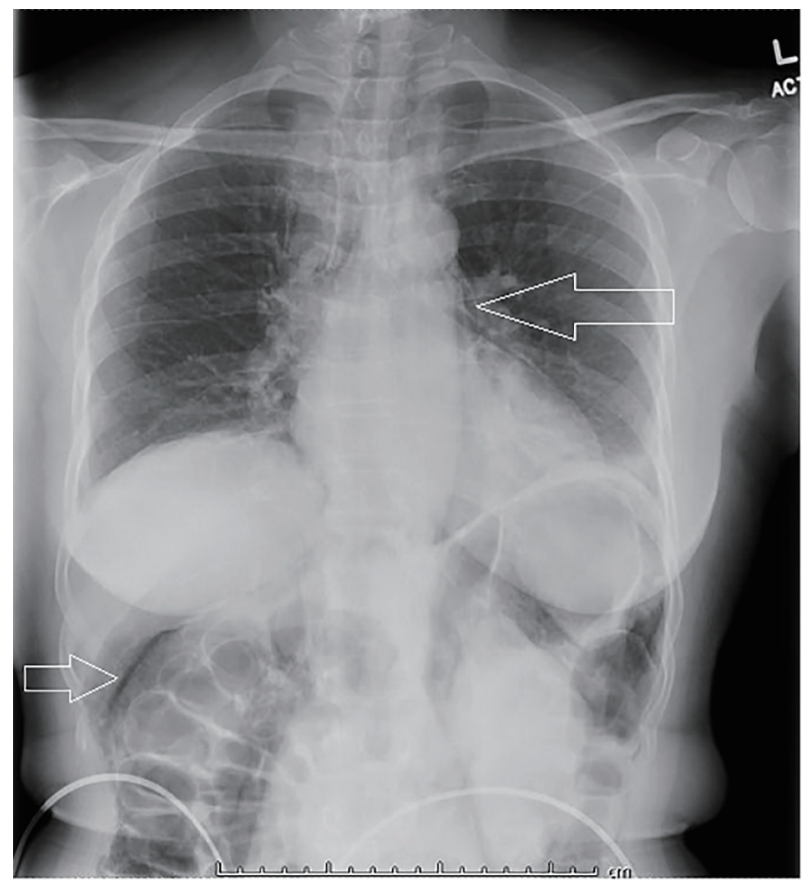

Figure 1. Plain radiography showing pneumoperitoneum as well as pneumomediastinum. 

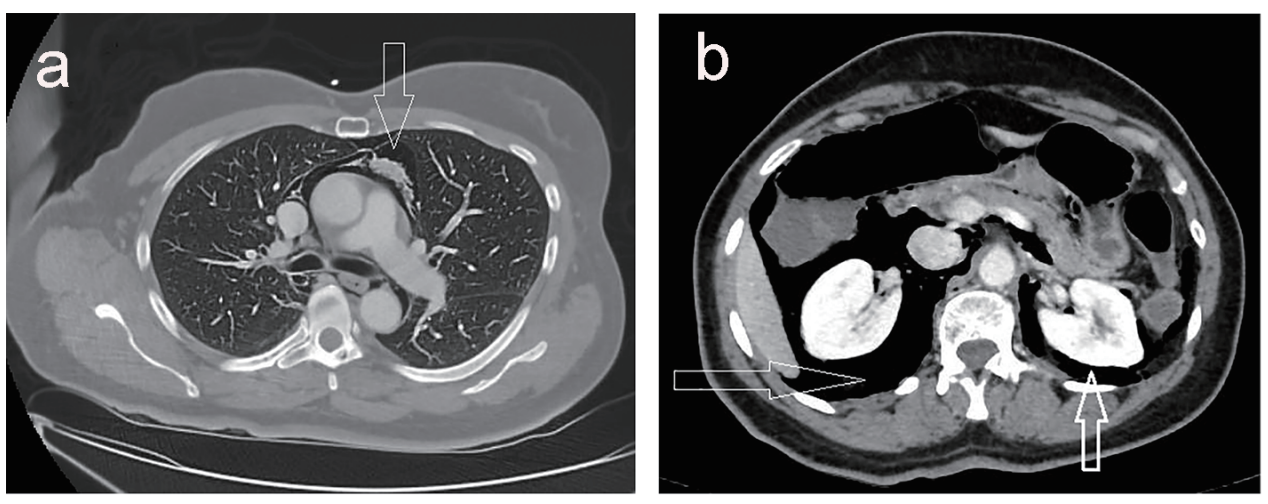

Figure 2. (a) CT scan of the chest showing massive pneumomediastinum. (b) CT scan of the abdomen and pelvis with massive free retroperitoneal and intraperitoneal air.

She was admitted to the intensive care unit for close monitoring and was managed conservatively with bowel rest, intravenous fluids and broad spectrum antibiotics. The patient condition improved without the need for surgical intervention, her diet was gradually advanced and a repeat $\mathrm{CT}$ scan of the chest, abdomen and pelvis after 4 days showed interval improvement of the pneumomediastinum and pneumoperitoneum. She was discharged in a stable condition and advised to follow up with outpatient medical clinic.

\section{Discussion}

The incidence of colorectal perforation following colonoscopy has been reported to range between $0.16 \%$ in diagnostic colonoscopies and $0.44 \%$ in therapeutic colonoscopies [1]. Risk factors for perforation include advanced age, inflammatory bowel disease, diverticulitis, malignant masses and performance of therapeutic procedures such as polypectomy [2-4].

Literature suggests sigmoid colon as the most commonly involved site for perforation followed by the cecum, which could be explained by anatomic variations, frequent location of diverticula, polyps and subsequent therapeutic interventions predisposing to thermal or mechanical injuries [5].

Three different mechanisms describe the cause of perforation: pneumatic perforation, mechanical perforation, and perforation associated with therapeutic colonoscopy [6]. Over distension by insufflated air can cause rupture of colon wall leading to pneumatic perforation while shaft or tip of the endoscope which excessively pressured the intestinal lumen can cause mechanical perforation. Therapeutic colonoscopy associated perforations likely result after colon polypectomy, pneumatic dilation, endoscopic mucosal resection and electroceutical injury caused by snares or hot biopsy forceps use. With polypectomy, this risk rises to $0.3-1 \%$, and with hydrostatic balloon dilatation of colonic strictures, higher rate (4.6\%) may be expected [7, 8]. Rarely, after colonoscopy, air can accumulate in certain extra-peritoneal body cavities such as the mediastinum, scrotum, subcutaneous tissues, or pleura [9]. The subcutaneous tissue offers the least resistance to expansion and thus, subcutaneous emphysema is usually the first to manifest [10]. The soft tissues in the neck are connected via a continu- um of facial planes with the mediastinal cavity, which creates the pneumoperitoneum. Furthermore, rupture of the mediastinal pleura due to a high pressure of insufflated air may lead to pneumothorax [11]. Cases involving both intra- and extra-peritoneal perforation following colonoscopy are extremely rare. Cirt et al in their literature search found only 11 such cases [8].

Patients with $\mathrm{CP}$ can present with symptoms and signs of peritonitis (mainly abdominal pain and tenderness) within several hours after the completion of colonoscopy. As the patients with therapeutic colonoscopies tend to have a smaller size of the perforation as compared to diagnostic, these have a delay in presentation compared [12-14]. The suspicion of CP should be kept in mind, if a patient has fever, abdominal pain or distention following the colonoscopic examination, even several days after the procedure. These patients can be diagnosed and treated for $\mathrm{CP}$ on the basis of generalized peritonitis without the radiologic evidence of perforation. In clinically in doubt, a plain X-ray of the abdomen should be taken to rule out intraperitoneal air. CT scanning and magnetic resonance imaging are also of great help to identify the free gas [15]. Water-soluble contrast enema can be used to confirm a concealed perforation.

The management of CP has been a controversial issue, though it is effectively managed by both conservative and nonconservative (operative) strategies [16, 17]. Conservative treatment is favored in patients with absence of peritonitis signs and hemodynamic stability [8]. These patients should be closely monitored for clinical improvement which is usually seen within 24 - $48 \mathrm{~h}$. If there is no improvement or worsening of condition, surgical interventions can be opted. Recently, another valid approach has been reported in patients with small lesions and without signs of peritonitis, where endoscopic clipping is followed by conservative treatment [18]. Surgical treatment is indicated when there is evidence of peritonitis signs, the presence of the distal obstruction to the perforation site and the worsening or no improvement after conservative treatment $[8,19]$.

\section{Conclusion}

In conclusion, during a colonoscopy, physicians should be aware of this rare complication as failure to recognize and treat 
such complications can be unsurprisingly fatal.

\section{Grant Support}

None.

\section{Financial Disclosures}

None.

\section{Conflicts of Interest}

None.

\section{References}

1. Kim HH, Park SJ, Lee SH, Park HU, Song CS, Park MI, Moon W. Efficacy of endoscopic submucosal resection with a ligation device for removing small rectal carcinoid tumor compared with endoscopic mucosal resection: analysis of 100 cases. Dig Endosc. 2012;24(3):159-163.

2. Zeno BR, Sahn SA. Colonoscopy-associated pneumothorax: a case of tension pneumothorax and review of the literature. Am J Med Sci. 2006;332(3):153-155.

3. Ho HC, Burchell S, Morris P, Yu M. Colon perforation, bilateral pneumothoraces, pneumopericardium, pneumomediastinum, and subcutaneous emphysema complicating endoscopic polypectomy: anatomic and management considerations. Am Surg. 1996;62(9):770-774.

4. Webb T. Pneumothorax and pneumomediastinum during colonoscopy. Anaesth Intensive Care. 1998;26(3):302304.

5. Panteris V, Haringsma J, Kuipers EJ. Colonoscopy perforation rate, mechanisms and outcome: from diagnostic to therapeutic colonoscopy. Endoscopy. 2009;41(11):941951.

6. Epstein O. Guidelines on complications of gastrointestinal endoscopy: Complications of colonoscopy. 2006, Nov. www.bsg.org.uk.

7. American Society for Gastrointestinal Endoscopy
Complications of Colonoscopy. Gastrointest Endosc. 2003;57:441-445.

8. Cirt N, de Lajarte-Thirouard AS, Olivie D, Pagenault M, Bretagne JF. [Subcutaneous emphysema, pneumomediastinum, pneumoperitoneum and retropneumoperitoneum following a colonoscopy with mucosectomy]. Gastroenterol Clin Biol. 2006;30(5):779-782.

9. Lee L, Saltzman JR. Overview of colonoscopy in adults. UpToDate (http://www.uptodate.com). 2013:1-56.

10. Frias Vilaca A, Reis AM, Vidal IM. The anatomical compartments and their connections as demonstrated by ectopic air. Insights Imaging. 2013;4(6):759-772.

11. Maunder RJ, Pierson DJ, Hudson LD. Subcutaneous and mediastinal emphysema. Pathophysiology, diagnosis, and management. Arch Intern Med. 1984;144(7):1447-1453.

12. Korman LY, Overholt BF, Box T, Winker CK. Perforation during colonoscopy in endoscopic ambulatory surgical centers. Gastrointest Endosc. 2003;58(4):554-557.

13. Teoh AY, Poon CM, Lee JF, Leong HT, Ng SS, Sung JJ, Lau JY. Outcomes and predictors of mortality and stoma formation in surgical management of colonoscopic perforations: a multicenter review. Arch Surg. 2009;144(1):913.

14. Luning TH, Keemers-Gels ME, Barendregt WB, Tan AC, Rosman C. Colonoscopic perforations: a review of 30,366 patients. Surg Endosc. 2007;21(6):994-997.

15. Iqbal CW, Cullinane DC, Schiller HJ, Sawyer MD, Zietlow SP, Farley DR. Surgical management and outcomes of 165 colonoscopic perforations from a single institution. Arch Surg. 2008;143(7):701-706; discussion 706707.

16. Avgerinos DV, Llaguna OH, Lo AY, Leitman IM. Evolving management of colonoscopic perforations. J Gastrointest Surg. 2008;12(10):1783-1789.

17. Donckier V, Andre R. Treatment of colon endoscopic perforations. Acta Chir Belg. 1993;93(2):60-62.

18. Park NS, Choi JH, Lee DH, Kim YJ, Kim ES, Jung SW, Koo JS, et al. Pneumoretroperitoneum, pneumomediastinum, peumopericardium, and subcutaneous emphysema after colonoscopic examination. Gut Liver. 2007;1(1):7981.

19. Lohsiriwat V. Colonoscopic perforation: incidence, risk factors, management and outcome. World J Gastroenterol. $2010 ; 16(4): 425-430$. 